\title{
The Interval Between Matches Significantly Influences Injury Risk in Field Hockey
}

\section{(ㄷ) (i) (우)}

\author{
Authors \\ Joel Mason'1, Anna Lina Rahlf', Andreas Groll², Kai Wellmann' ${ }^{1}$, Astrid Junge ${ }^{3,4}$, Astrid Zech ${ }^{1}$
}

\section{Affiliations}

1 Institute for Sports Science, University of Jena Jena, Germany

2 Department of Statistics, TU Dortmund University, Dortmund, Germany

3 MSH Medical School Hamburg, Prevention and Sport, Hamburg, Germany

4 Schulthess Klinik, Swiss Concussion Center, Zurich, Switzerland

Key words

match density, fixture congestion, injury, team sport, schedule

accepted $\quad 01.07 .2021$

published online 17.09 .2021

Bibliography

Int J Sports Med 2022; 43: 262-268

DOI 10.1055/a-1577-3451

ISSN $0172-4622$

(C) 2021. The Author(s).

This is an open access article published by Thieme under the terms of the Creative Commons Attribution-NonDerivative-NonCommercial-License, permitting copying and reproduction so long as the original work is given appropriate credit. Contents may not be used for commercial purposes, or adapted, remixed, transformed or built upon. (https://creativecommons.org/licenses/ by-nc-nd/4.0/)

Georg Thieme Verlag, Rüdigerstraße 14,

70469 Stuttgart, Germany

\author{
Correspondence \\ Joel Mason \\ Institute for Sports Science, \\ Friedrich Schiller University Jena, \\ Seidelstrasse 20 \\ Jena 07743 \\ Germany \\ Tel.: + 493631 9-45713, \\ joel.mason@uni-jena.de
}

\section{ABSTRACT}

Fixture congestion increases injury risk in football, but how it impacts other sports is unclear. The aim of this study was to identify associations between match density and injury incidence in field hockey players. Injury data from a prospective cohort study of professional and youth players was analysed in two ways. Inter-match intervals were clustered into $<24$-hours, 3-7-days, and 13 + days, and injury rate ratios (IRR) were calculated to identify differences between clusters in match injuries. Separately, a Lasso-penalised Poisson regression model was used to determine the association between match load across the previous 24-hours, 3-days, 7-days and 14-days, and match and training injuries. Injury rates in matches within 24-hours of the previous match were mostly significantly higher when compared to matches after 3-7-days (IRRs: 3.78; 6.77, $\mathrm{P}=0.003 ; 0.005)$. While a higher match exposure in the preceding 24-hour and 3-day periods was associated with higher combined match and training injury rates $(\hat{\beta}=0.0001 ; 0.0018)$, a higher match exposure in the previous 7 -and 14 -day periods was associated with a reduced injury rate $(\hat{\beta}=-0.0001$; $-0.0005)$. Due to the increased injury risk in matches 3 -days and especially 24-hours following the previous fixture, match distribution should be cautiously planned.

\section{Introduction}

In team sports, the distribution of matches across a given time period presents a complex challenge when planning for the competing demands of recovery from one match and preparation for the next. An incompatibility between recovery timeframes [1-4] and the interval between matches can impact physical performance as well as the overall outcome of matches. For example, shorter-thannormal intermatch periods reduce acceleration frequency in youth footballers [5] and reduce the likelihood of winning games in the National Basketball Association (NBA) [6]. 
Importantly, a higher match density has also been associated with an increase in the rate of injuries [7-11]. Professional football players with intermatch intervals of 6-10 days have muscle injury rates $20 \%$ below the rates observed in players who had three or fewer days between matches [8]. Similarly, playing two football matches per week dramatically raises the injury rate compared with just one match per week [11]. Although these findings emphasise the need for sufficient recovery between football matches, the transferability of these findings to other sports is limited. Multiple studies report that the addition of mid-week American football matches has no influence on injury rates $[12,13]$, although the interval between matches still remains over three days. Regardless of mixed findings and uncertainty regarding the critical time windows for an increased injury risk, growing concerns over increasing player workload demands across the football season [14] were further piqued when Liverpool played matches on consecutive days in 2019. Despite the 24-hour window hovering firmly below all recommendations for complete recovery [1-4], it is frequently used in team sport leagues and tournaments. Teramoto et al. observed that playing games on consecutive days was a significant predictor of frequent injuries in NBA players [15], and although the lack of clear exposure data and incidence rates limits these findings, they do indicate the possibility of an increased injury risk when matches are played within 24 hours of each other.

A popular team sport which regularly implements games on consecutive days is field hockey $[16,17]$. Despite evidence that high-speed running decreases during hockey match congestion [16], it is unclear how the intermatch interval and total match exposure influence injury rates in field hockey. Therefore, the purpose of this study was to perform a secondary time-related analysis of prospectively collected and previously published general injury data [18] in order to 1) identify if different intermatch intervals influence the rate of match injuries, and 2) determine associations between match exposure across intervals of 24 hours, 3 days, 7 days and 14 days and injury occurrence in elite adult and highlevel youth field hockey players.

\section{Materials and Methods}

A prospective study was conducted during the field-hockey season of 2015/16. Twenty-eight field-hockey clubs were contacted via the regional hockey federation and invited to participate. The coaches of interested teams were consulted by mail and phone to give further information about the study process and to clarify the inclusion criteria. Male and female players of the national first, regional, and youth divisions were included. After verification of eligibility, participants or their legal representatives provided informed written consent. The study was approved by the local ethics committee (No. PV 4893), adhered to the guidelines of the Declaration of Helsinki (1975), and meets the ethical standards of the International Journal of Sports Medicine [19]. The epidemiology of the general injury data with details on training vs. game, indoor vs. outdoor, female vs. male, the severity, injury types, and body location has been previously published [18].

\section{Exposure and injury registration}

During a complete season (August 2015 - March 2016), exposure time and injury registration was performed prospectively by the coach and medical staff of teams. The exposure time of each player was recorded in minutes for each individual practice and match in a standardised report form, modified in accordance with Fuller et al. [20]. One team reported individual game exposure data and all other teams reported the full game time for a player participating in a game. In case of missing individual exposure data, the player exposure was determined to be the full participation time of $70 \mathrm{~min}$ for outdoor games and 60 min during indoor games. Data collection was performed daily by the coaches and was sent weekly to the responsible researcher.

Injury registration was conducted by a qualified member of team staff on a standardised injury form [21]. Any complaint with time loss of one or more subsequent training or match days, including acute and overuse complaints, was registered. Injuries were separately reported for training, matches, or no-exposure periods. Injuries that were related to hockey exposure but reported during a day without training or a match were assigned to the exposure (training or match) of the previous day. Injuries that were reported during a period of two days or longer without training or a match were also counted but assigned to a third category (no exposure). Injury severity (severe injuries $>21$ days [22]) and types (e. g. concussion, sprain) were recorded.

\section{Data analysis and statistics}

Exposure and injury data were collected in a database (Excel for Mac 11, version 14.7.1; Microsoft Cooperation, Redmond, WA, USA) and all statistical analyses were conducted in the statistical software program $R$ [23]. The analysis was performed in two independent parts according to the two objectives. Firstly, to identify if different intermatch intervals influence the rate of match injuries, the match exposure hours were counted for three different time-dependent categories: a) matches within 24 hours of a previous match, b) matches 3-7 days after the preceding match, and c) matches 13 days or more following the previous match. For each match, the number of overall injuries, lower extremity (LE) injuries, severe injuries, and muscle injuries of each team was counted. Match injury incidence for each category of intermatch period was defined as the number of injuries per 1000 match hours (number of injuries / exposure hours $\times 1000)$. The injury rate ratio (IRR) and confidence interval $(\mathrm{Cl})$ was used to express the effects between the categories.

To determine associations between previous match exposure and injury incidence for each day of the season (regardless whether the injury occurred during training, match, or no-exposure days), the rolling cumulative sum of previous match exposure hours was calculated for the following time intervals: a) previous 24 hours, b) previous 3 days, c) previous 7 days and d) previous 14 days. Then the time-dependent associations between the previous match exposure intervals (independent variables) and injuries were analysed with a Lasso-penalized Poisson regression model [24, 25] using the glmnet R package. The Lasso approach refers to L1-penalization on the regression coefficients' absolute values. Hence, all coefficients are generally shrunk towards zero, and less important effects can even be set to exactly zero. The penalization strength is controlled 
by a penalty parameter $\lambda$ : for large values of $\lambda$, only the coefficients of the most influential predictors are retained, and all other effects are shrunk to zero, whereas for lower values of $\lambda$, shrinkage is less severe. Hence, $\lambda$ is a tuning parameter and controls how many covariates are selected to be relevant. Thus, Lasso typically achieves implicit variable selection. In general, the major advantages of using the Lasso are that it is less affected by multi-collinearity issues, reduces the prediction error, and leads to lower mean squared errors; see Friedman et al. [26]. Some of the above-mentioned covariates exhibit a substantial amount of multicollinearity, particularly the match exposure variables for different time periods. However, the Lasso regularization technique is more robust against multicollinearity issues [26]. A separate analysis of training vs. match, indoor vs. outdoor, or different injury types was not performed since these data can be found in a previous publication [18].

\section{Results}

The final analysis included 191 (100 national first division players, and 91 combined youth and regional team players), for a combined total of 24089.3 hours exposure ( 3663.3 hours match exposure and 20426 hours training exposure). A total of 99 injuries were reported for a total injury incidence of 4.1 per 1000 hours of exposure. Detailed information on exposure and injury data is provided in $>$ Table 1.

\section{Intermatch intervals and match injury incidence}

Injury incidence rates for each rest-interval cluster and injury rate ratios comparing injury incidence between clusters are detailed in

\section{- Table 2.}

A significant 3.78-fold $(95 \% \mathrm{Cl} 1.46,9.69, \mathrm{P}=0.003)$ increase in total injury rate was observed when matches were played within 24 hours of a previous match compared to a 3-7 day interval, but the 1.94-fold increase in injury rate compared to a $13+$ day intermatch interval was non-significant ( $95 \% \mathrm{Cl} 0.71,5.34, \mathrm{P}=0.267)$. LE injury was 6.8 -fold $(95 \% \mathrm{Cl} 1.46,31.31, \mathrm{P}=0.005)$ higher in matches played within 24 hours compared to matches with an interval of 3-7days ( $95 \% \mathrm{Cl} 0.63,3.47, \mathrm{P}=0.152$ ), but there was no significant difference between LE injury rates in the 24-hour window vs. the 13 + day window (2.91-fold increase, $95 \% \mathrm{Cl} 0.63,3.47$, $P=0.152)$. Severe injury incidence rates did not differ significantly between time windows. No significant differences were observed in any type of injury incidence rate between matches with a 3-to 7-day intermatch interval vs. matches with $>13$ days in between $(P=0.267 ; 0.902)$.

\section{Associations between previous match exposure and daily injury incidence}

The Lasso-penalized Poisson regression model identified multiple associations between recent match exposure and match/training injury occurrence ( $\triangleright$ Table 3 ). In simple terms, the results of the Lasso analysis can be interpreted in the current context as follows: a higher $\beta$ value signifies a higher injury incidence, whereas a lower $\beta$ value signifies a lower injury incidence. A higher match exposure in the previous 24 hours was associated with general injury incidence $(\hat{\beta}=0.0015)$, LE injury incidence $(\hat{\beta}=0.0018)$, severe injury
- Table 1 Description of included variables.

\begin{tabular}{|c|c|c|c|}
\hline & Total & $\begin{array}{l}\text { Male } \\
\text { Players }\end{array}$ & $\begin{array}{l}\text { Female } \\
\text { Players }\end{array}$ \\
\hline Teams (n) & 8 & 5 & 3 \\
\hline Players (n) & 191 & 133 & 58 \\
\hline Days in season (SD) & $254(25)$ & $254(15)$ & $237(33)$ \\
\hline $\begin{array}{l}\text { Match exposure } \\
\text { (hours) }\end{array}$ & 3663 & 2714 & 949 \\
\hline $\begin{array}{l}\text { Training + match } \\
\text { exposure (hours) }\end{array}$ & 24135 & 17123 & 7012 \\
\hline $\begin{array}{l}\text { Total number of } \\
\text { matches }\end{array}$ & 280 & 182 & 98 \\
\hline $\begin{array}{l}\text { Matches }<24 \text { hours } \\
\text { after previous match } \\
\text { (n) }\end{array}$ & 85 & 63 & 22 \\
\hline $\begin{array}{l}\text { Matches 3-7 days after } \\
\text { previous match (n) }\end{array}$ & 121 & 72 & 49 \\
\hline $\begin{array}{l}\text { Matches }>13 \text { days after } \\
\text { previous match }(\mathrm{n})\end{array}$ & 49 & 32 & 17 \\
\hline \multicolumn{4}{|l|}{ Total injuries } \\
\hline Number & 99 & 71 & 28 \\
\hline $\begin{array}{l}\text { Incidence (inju- } \\
\text { ries/1000 h) }\end{array}$ & 4.1 & 4.1 & 4.0 \\
\hline \multicolumn{4}{|l|}{$\begin{array}{l}\text { Lower extremity } \\
\text { injuries }\end{array}$} \\
\hline Number & 55 & 42 & 13 \\
\hline $\begin{array}{l}\text { Incidence (inju- } \\
\text { ries } / 1000 \mathrm{~h} \text { ) }\end{array}$ & 2.3 & 2.5 & 1.9 \\
\hline \multicolumn{4}{|l|}{ Severe injuries } \\
\hline Number & 33 & 22 & 11 \\
\hline $\begin{array}{l}\text { Incidence (inju- } \\
\text { ries/1000 h) }\end{array}$ & 1.4 & 1.3 & 1.6 \\
\hline \multicolumn{4}{|l|}{ Muscular injuries } \\
\hline Number & 23 & 21 & 2 \\
\hline $\begin{array}{l}\text { Incidence (inju- } \\
\text { ries/1000 h) }\end{array}$ & 1.0 & 1.2 & 0.3 \\
\hline
\end{tabular}

incidence $(\hat{\beta}=0.0012)$, and muscle injury incidence $(\hat{\beta}=0.0007)$. A higher match exposure in the previous 3 days was also associated with general injury incidence $(\hat{\beta}=0.0001)$ and LE injury incidence $(0.0001)$ but not with severe injury or muscle injury incidence. Conversely, higher match exposures in the previous 7 - and 14-day periods were associated with a decrease in injury incidence across multiple categories. Higher match exposure in the previous 7 days was associated with a decrease in general injury incidence ( $-0.0001)$, LE injury incidence $(\hat{\beta}=-0.0005)$, and muscle injury incidence $(\hat{\beta}=-0.00005)$ but not associated with severe injury incidence. A higher match exposure in the previous 14 days was associated with a decreased risk in general injury incidence $(\hat{\beta}=-0.0002)$, LE injury $(\hat{\beta}=-0.0001)$, and severe injury incidence $(\hat{\beta}=0-0.00003)$, but no association between muscle injury and match exposure over 14 days was identified.

\section{Day of the season}

The day of the season was also identified as relevant for injury incidence by the regression model ( $\vee$ Table 3 ). Specifically, total inju- 
- Table 2 Comparison of game injury incidence (number of injuries/1000 exposure h) for games with (a) about $24 \mathrm{~h}$ rest after a previous game, (b) 3-7 days rest, and (c) more than 13 days rest.

\begin{tabular}{|c|c|c|c|c|c|c|c|}
\hline & \multirow[b]{2}{*}{$\begin{array}{l}\text { All } \\
\text { games }\end{array}$} & \multirow[t]{2}{*}{$=\mid<24 \mathrm{~h}$ rest } & \multirow{2}{*}{$\begin{array}{l}3-7 \text { days } \\
\text { rest }\end{array}$} & \multirow{2}{*}{$\begin{array}{l}>13 \text { days } \\
\text { rest }\end{array}$} & \multicolumn{3}{|c|}{ IRR (95\% CI) } \\
\hline & & & & & $\begin{array}{l}24 \text { h vs. } 3-7 \\
\text { days rest }\end{array}$ & $\begin{array}{l}24 \mathrm{~h} \text { vs. }>13 \\
\text { days rest }\end{array}$ & $\begin{array}{l}3-7 \text { days } \\
\text { vs. >13 days } \\
\text { rest }\end{array}$ \\
\hline General injuries & 7.92 & 14.25 & 3.79 & 7.35 & $\begin{array}{l}3.78[1.46,9.69] \\
(P=0.003)\end{array}$ & $\begin{array}{l}1.94[0.71,5.34] \\
(P=0.191)\end{array}$ & $\begin{array}{l}0.52[0.16, \\
1.69](P=0.267)\end{array}$ \\
\hline $\begin{array}{l}\text { Lower extremity } \\
\text { injuries }\end{array}$ & 3.82 & 8.55 & 1.26 & 2.94 & $\begin{array}{l}6.77[1.46 \\
31.31] \\
(P=0.005)\end{array}$ & $\begin{array}{l}2.91[0.63,3.47] \\
(P=0.152)\end{array}$ & $\begin{array}{l}0.43[0.06 \\
3.05](P=0.385)\end{array}$ \\
\hline Severe injuries & 2.73 & 4.75 & 1.26 & 1.47 & $\begin{array}{l}3.76[0.73 \\
19.37] \\
(P=0.089)\end{array}$ & $\begin{array}{l}3.23[0.38, \\
27.68] \\
(P=0.257)\end{array}$ & $\begin{array}{l}0.86[0.08, \\
9.49] \\
(P=0.902)\end{array}$ \\
\hline
\end{tabular}

- Table 3 Time-dependent variables identified by the regression model to influence the injury incidence. A positive $\beta$ indicates that a higher match exposure variable (cumulative match minutes per team) or day of the season is associated with an increased number of injuries. Missing $\beta$ indicates no influence of the variable was identified by the regression model.

\begin{tabular}{|l|c|c|c|c|}
\hline \multirow{2}{*}{} & \multicolumn{3}{c|}{$\beta$-values } \\
\cline { 2 - 4 } & All injuries & Lower extremity injuries & Severe injuries \\
\hline Day of the season & 0.0004 & 0.0011 & -0.0013 \\
\hline Gender & - & - & - & \\
\hline Match exposure & & & -0.4348 \\
\hline previous 24 hours & 0.0015 & 0.0018 & 0.0012 \\
\hline previous 3 days & 0.0001 & 0.0001 & - \\
\hline previous 7 days & -0.0001 & -0.0005 & - & - \\
\hline previous 14 days & -0.0002 & -0.0001 & -0.007 \\
\hline
\end{tabular}

ries $(\hat{\beta}=0.00004)$, LE injury $(\hat{\beta}=0.0011)$, and muscle injuries ( $\hat{\beta}=0.0014$ ) were more likely to occur as the season progressed. However, severe injuries were less likely to occur later in the season $(\hat{\beta}=-0.0013)$.

\section{Discussion}

The aim of this study was to characterise the relationship between recent match exposure and injury in field hockey players, with particular focus on the 24-hour window following matches. The two analysis models yielded complementary results, largely indicating that when acute match exposure is high and the intermatch rest interval is low, the general risk of injury is substantially higher. Key findings include that 1 ) matches played within 24 hours of another match had an injury risk 3.76-6.77 times higher than matches played within a 3-7 day period; 2 ) higher match exposures in the preceding 24-hour and, to a lesser extent, 3-day periods were associated with higher training and match injury rates; 3 ) a higher match exposure in the previous 7 -and 14-day periods was associated with a reduced injury incidence; and $\mathbf{4}$ ) injury incidence increased as the season progressed.

Although this is the first study examining the relationship between recent match exposure and injury in field hockey, the current findings corroborate general evidence from professional football that when the frequency of gameplay is intensified, so too is the injury rate [7-11]. The three-day period following a match has previously been identified as a critical window for an increase in subsequent match muscle-injury rates of professional football teams [8]. Although a similar association between 3-day exposure and muscle injury was not observed in this study, there was an association between higher 3-day match exposure and increased incidence of general and LE injuries. Unique to this study, we found that playing a subsequent match within 24 hours produced an injury risk between 3.8-6.8 times higher than the risk observed in matches preceded by a 3-/to7-day break. This may explain why hockey tournaments appear to produce higher injury rates than a regular hockey season where matches may be more evenly distributed throughout a week on average $[18,27]$.

\section{Higher match exposure in the preceding 24 hours increases incidence of all and specific injuries}

The increase in both general and classification-specific injury risk associated with lower intermatch intervals and higher recent match exposure is likely driven by insufficient recovery between matches. The demands of invasion team sports produce a cascade of stress responses that do not fully restore to baseline levels until $36-96$ hours following match play $[1-4,28]$. This general recovery timeline has previously been used to explain the increased injury risk during football fixture congestion [8]. Although there is comparatively limited information regarding recovery timelines following hockey matches, there is evidence suggesting that the locomotive demands of field hockey are similar to those of professional football [29], and it is therefore conceivable that the recovery timelines are not excessively dissimilar.

An additional explanation is that match-induced alterations to underlying physiology can also generate short-term deficits in neu- 
romuscular performance, which may contribute to an increase in acute injury risk associated with a high recent match exposure. For example, eccentric hamstring strength, which has been demonstrated to protect against hamstring injury [30], is compromised for up to 96 hours following football matches [2]. This is particularly relevant given the high incidence of thigh injuries in field hockey [18]. The significance of enhanced neuromuscular control abilities for lower injury incidence in team sports is also demonstrated by the accumulating evidence for the preventative effects of regular neuromuscular training programmes [31-33].

\section{Higher match exposure over the preceding 7 and 14 day windows reduces total injury incidence}

Unlike the 24-hour and 3-day windows, a higher match exposure over 7 and 14-day periods instead offered a protective effect against injury. This aligns with evidence that larger exposure to high-speed running and higher training loads over a period of weeks reduces injury incidence in team sports via an increased tolerance to specific load [34,35]. Although the tipping point where match exposure shifts from having a protective effect against injuries to a detrimental impact is likely to be influenced by a complex range of factors and is currently unknown, it is clear that playing a subsequent match within 24 hours is uniquely detrimental to player welfare beyond other intermatch intervals.

An additional hypothesis is that players who had not played because of injury in the previous 7-14 days were at a higher risk of injury when returning to match play perhaps as a consequence of premature return to play [36-38].

\section{Total injury incidence increases as the stage of the season progresses}

We also observed an increase in injury incidence as the season progressed, which replicates findings from professional German football that match injuries are more frequent in the late stages of the season [39]. This could be explained by the cumulative fatigue players develop throughout a season, which may be particularly accelerated during match congestion. Progressive declines in selfperceived wellness, including sleep quality, perceived recovery and fatigue, are reported in field hockey players throughout extended match congestion periods $[17,40]$. Such decays in perceived wellness are associated with increased injury risk across most team sports [41].

Further, field hockey players experience $10-14 \%$ decreases in muscular strength across a playing season [42]. Although not all neuromuscular performance risk factors for team sport injury are reduced following a field hockey season [43], a demanding competition schedule not only compromises recovery but also limits opportunities to implement in-season training load. This plausibly leads to inevitable decrements in acute and chronic neuromuscular performance factors $[42,44]$ which potentially impact the likelihood of field hockey injury as the season progresses.

\section{Limitations}

Our analyses did not consider training exposure, and therefore the influence of training load prescription between matches is not factored into the injury incidence equation, despite almost certainly playing a role. The assumption that all players are exposed to the same training therefore limits our findings. Importantly, the sample size was insufficient to detect further relationships between match exposure and muscle injury risk specifically, as similar studies observing such a relationship in football have utilised considerably larger datasets [8]. Intermatch interval is highly unlikely to influence contact and laceration injuries, and therefore combining injuries into a 'general injury' category is a key limitation of our study. We also did not distinguish between indoor vs. outdoor or training vs. match injuries in this publication since a sub-analysis would have led to an insufficient number of injuries in each category, therefore preventing valid conclusions to be drawn. Another limitation is the lack of exact individual playing exposure times including 'flying substitutions' during games in most teams. This may have resulted in higher total game exposure times but should not have led to systematic error since the conditions were the same in the independent (exposure-related) variables.

\section{Applications, future directions and conclusion}

Associations responsible for organising the distribution of matches over a tournament and a season are encouraged to avoid scheduling matches on consecutive days where possible. For coaches and training staff, these findings emphasise the need for systematic recovery monitoring in order to make informed player availability decisions which may mitigate the injury risk during matches played in rapid succession. Further, the rate of recovery following matches is influenced by the physical capacities of the athlete [45], underlining the need to rigorously develop physical capacities during the pre-season.

Future research should use larger datasets in various team sports to confirm our findings, analyse narrower intermatch rest intervals, and monitor the effects of different recovery and in-season training load strategies on injury rates during periods of match congestion and throughout an entire season.

In sum, this study provides new insight into the temporal relationship between match load and injury, identifying that the 24hour period following a match is a particularly hazardous window for all types of subsequent injuries in field hockey players and should therefore be off-limits for subsequent team sport match play.

\section{Acknowledgements}

The authors would like to sincerely thank all teams and players who participated in the study.

\section{Funding}

This study was funded by the German Federal Institute for Sport Science (grant number 2515BI0111).

Conflicts of Interest

No additional conflicts of interest are declared. The results of this study are presented honestly, and without fabrication, falsification, or inappropriate data manipulation. 


\section{References}

[1] Silva JR, Rumpf MC, Hertzog M et al. Acute and residual soccer match-related fatigue: A systematic review and meta-analysis. Sports Med 2018; 48: 539-583

[2] Rhodes D, McNaughton L, Greig M. The temporal pattern of recovery in eccentric hamstring strength post-soccer specific fatigue. Res Sports Med 2019; 27: 339-350

[3] Ispirlidis I, Fatouros IG, Jamurtas AZ et al. Time-course of changes in inflammatory and performance responses following a soccer game. Clin J Sport Med 2008; 18: 423-431

[4] Nédélec M, McCall A, Carling C et al. Recovery in soccer. Sports Med 2012; 42: 997-1015

[5] Arruda AF, Carling C, Zanetti V et al. Effects of a very congested match schedule on body-load impacts, accelerations, and running measures in youth soccer players. Int ] Sports Physiol Perform 2015; 10: 248-252

[6] Esteves PT, Mikolajec K, Schelling X et al. Basketball performance is affected by the schedule congestion: NBA back-to-backs under the microscope. Eur J Sport Sci 2021; 21: 26-35

[7] Bengtsson H, Ekstrand J, Hägglund M. Muscle injury rates in professional football increase with fixture congestion: An 11-year follow-up of the UEFA Champions League injury study. $\mathrm{Br}$ J Sports Med 2013; 47: 743-747

[8] Bengtsson H, Ekstrand J, Waldén $\mathrm{M}$ et al. Muscle injury rate in professional football is higher in matches played within 5 days since the previous match: A 14-year prospective study with more than 130000 match observations. Br J Sports Med 2018; 52: 1116-1122

[9] Carling C, McCall A, Le Gall F et al. The impact of short periods of match congestion on injury risk and patterns in an elite football club. $\mathrm{Br}$ J Sports Med 2016; 50: 764-768

[10] Dellal A, Lago-Peñas C, Rey E et al. The effects of a congested fixture period on physical performance, technical activity and injury rate during matches in a professional soccer team. Br J Sports Med 2015; 49: 390-394

[11] Dupont G, Nedelec M, McCall A et al. Effect of 2 soccer matches in a week on physical performance and injury rate. Am J Sports Med 2010; 38: 1752-1758

[12] Perez JR, Burke J, Zalikha AK et al. The effect of Thursday night games on in-game injury rates in the National Football League. Am J Sports Med 2020; 48: 1999-2003

[13] Baker HP, Young-Hoon Lee K, Dayton SR et al. Thursday Night Football's impact on all-cause injuries in NFL players during 20122017. Phys Sportsmed 2019; 47: 350-352

[14] The Fédération Internationale des Associations de Footballeurs Professionnels. At the limit: Player workload in elite professional men's football. [Internet]. 2019 [cited October 24 20]. Available from: https://www.fifpro.org/media/bffctrd1/at

[15] Teramoto M, Cross CL, Cushman DM et al. Game injuries in relation to game schedules in the National Basketball Association. J Sci Med Sport 2017; 20: 230-235

[16] Romero-Moraleda B, Morencos-Martínez E, Torres-Ronda L et al. Analysis of congested schedule on competition external load in field hockey. Rev Int Cienc Deporte 2020; 16: 143-152

[17] Ihsan M, Tan F, Sahrom S et al. Pre-match perceived wellness highly associates with match running performances during an international field hockey tournament. Eur J Sport Sci 2017; 17: 593-602

[18] Hollander K, Wellmann K, zu Eulenburg C et al. Epidemiology of injuries in outdoor and indoor hockey players over one season: A prospective cohort study. Br J Sports Med 2018; 52: 1091-1096

[19] Harriss DJ, Macsween A, Atkinson G. Ethical standards in sport and exercise science research: 2020 update. Int J Sports Med 2019; 40: 813-817
[20] Fuller CW, Ekstrand J, Junge A et al. Consensus statement on injury definitions and data collection procedures in studies of football (soccer) injuries. Scand J Med Sci Sports 2006; 16: 83-92

[21] Junge A, Engebretsen L, Alonso JM. Injury surveillance in multi-sport events: The International Olympic Committee approach. $\mathrm{Br}$ J Sports Med 2008; 42: 413-421

[22] Junge A, Dvorak ]. Influence of definition and data collection on the incidence of injuries in football. Am J Sports Med 2000; 28: 40-46

[23] R Core Team. R: A Language and Environment for Statistical Computing. Vienna, Austria. R Foundation for Statistical Computing, 2020

[24] Tibshirani R. Regression shrinkage and selection via the lasso. J R Stat Soc Series B Stat Methodol 1996; 58: 267-288

[25] Friedman ], Hastie T, Tibshirani R. Regularization paths for generalized linear models via coordinate descent. J Stat Softw 2010; 33: 1-22

[26] Friedman J, Hastie T, Tibshiran R. The Elements of Statistical Learning. New York: Springer Series in Statistics; 2001

[27] Theilen TM, Mueller-Eising W, Bettink PW et al. Injury data of major international field hockey tournaments. Br J Sports Med 2016; 50: 657-660

[28] Howle K, Waterson A, Duffield R. Recovery profiles following single and multiple matches per week in professional football. Eur J Sport Sci 2019; 19: 1303-1311

[29] Spencer M, Lawrence S, Rechichi C et al. Time-motion analysis of elite field hockey, with special reference to repeated-sprint activity. J Sports Sci 2014; 22: 843-850

[30] Opar D, Williams M, Timmins R et al. Eccentric hamstring strength and hamstring injury risk in Australian footballers. Med Sci Sports Exerc 2015; 47: 857-865

[31] Hübscher M, Zech A, Pfeifer K et al. Neuromuscular training for sports injury prevention: A systematic review. Med Sci Sports Exerc. 2010; 42: 413-421

[32] Steib S, Rahlf AL, Pfeifer K et al. Dose-response relationship of neuromuscular training for injury prevention in youth athletes: A meta-analysis. Front Physiol 2017; 8: 920

[33] Rahlf AL, Zech A. Comparison of 10 vs. 20 min neuromuscular training for the prevention of lower extremity injuries in male youth football: A cluster randomised controlled trial. J Sports Sci 2020; 38: 2177-2185

[34] Colby MJ, Dawson B, Peeling P et al. Repeated exposure to established high risk workload scenarios improves non-contact injury prediction in Elite Australian footballers. Int J Sports Physiol Perform 2018; 13: $1130-1135$

[35] Malone S, Roe M, Doran DA et al. Protection against spikes in workload with aerobic fitness and playing experience: The role of the acute: Chronic workload ratio on injury risk in elite Gaelic football. Int J Sports Physiol Perform 2016; 12: 393-401

[36] Fulton ], Wright $\mathrm{K}$, Kelly $\mathrm{M}$ et al. Injury risk is altered by previous injury: A systematic review of the literature and presentation of causative neuromuscular factors. Int J Sports Phys Ther 2014; 9: 583-595

[37] Gajhede-Knudsen M, Ekstrand J, Magnusson $\mathrm{H}$ et al. Recurrence of Achilles tendon injuries in elite male football players is more common after early return to play: An 11-year follow-up of the UEFA Champions League injury study. Br J Sports Med 2013; 47: 763-768

[38] Ekstrand J, Healy JC, Waldén M et al. Hamstring muscle injuries in professional football: The correlation of MRI findings with return to play. BrJ Sports Med 2012; 46: 112-117

[39] Leventer L, Eek F, Lames M. Intra-seasonal variation of injury patterns among German Bundesliga soccer players. J Sci Med Sport 2019; 22: 661-666

[40] Vescovi JD, Klas A, Mandic I. Investigating the relationships between load and recovery in women's field hockey-Female Athletes in Motion (FAiM) study. Int J Perform Anal Sport 2019; 19: 672-682 
[41] van der Does $\mathrm{H}$, Brink M, Otter R et al. Injury risk is increased by changes in perceived recovery of team sport players. Clin J Sport Med 2017; 27: 46-51

[42] Astorino TA, Tam PA, Rietschel JC et al. Changes in physical fitness parameters during a competitive field hockey season. J Strength Cond Res 2004; 18: 850-854

[43] Hoch MC, Welsch LA, Hartley EM et al. Y-balance test performance after a competitive field hockey season: A pretest-posttest study. J Sport Rehabil 2017; 26. doi:10.1123/jsr.2017-0004
[44] Talpey SW, Axtell R, Gardner E et al. Changes in lower body muscular performance following a season of NCAA division I men's lacrosse. Sports (Basel) 2019; 7: 18

[45] Johnston RD, Gabbett T], Jenkins DG et al. Influence of physical qualities on post-match fatigue in rugby league players. J Sci Med Sport 2015; 18: 209-221 